\title{
Ketamine-diazepam protocol for intravenous sedation: The cosmetic surgery hospital experience
}

\author{
Adel Quttainah MD FRCSC, Lloyd Carlsen MD FRCSC, Sandra Voice MD FRCSC, John Taylor MD FRCSC
}

\begin{abstract}
A Quttainah, L Carlsen, S Voice, J Taylor. Ketamine-diazepam protocol for intravenous sedation: The cosmetic surgery hospital experience. Can J Plast Surg 2004;12(3):141-143.
\end{abstract}

Rising hospital costs and operating room scheduling difficulties have influenced plastic surgeons to rely more often on intravenous sedation in office surgical settings. The use of ketamine as an intravenous sedation agent has enjoyed some popularity, but this has been far from universal. Its reputation for producing psychological sequelae such as nightmares, flashbacks and schizophrenic-like reactions have made many anesthesiologists and plastic surgeons reluctant to use this drug.

The authors' experience using a ketamine/diazepam protocol with approximately 11,400 patients since 1971 at the Cosmetic Surgery Hospital in Woodbridge, Ontario is presented. The methodology consists of intravenous diazepam followed with low-dose ketamine $(0.5 \mathrm{mg} / \mathrm{kg}$ to a maximum of $40 \mathrm{mg}) 2 \mathrm{~min}$ later. This provides the surgeon with a period of profound amnesia to allow for infiltration of the local anesthetic. It is this local anesthetic delivered during the dissociative state that provides prolonged analgesia throughout the surgery. The patient is maintained throughout the procedure with increments of diazepam and midazolam.

This protocol is found to be effective, reliable and reproducible, and the experience of the patient and plastic surgeon has been overwhelmingly favourable.

Key Words: Intravenous sedation; Ketamine; Office anesthesia
Le protocole de sédation intraveineuse à base de kétamine et de diazépam : chirurgie esthétique à l'hôpital

Laugmentation des coûts hospitaliers et les difficultés d'utilisation des salles d'opération ont poussé les chirurgiens esthétiques à recourir plus souvent à la sédation intraveineuse pour pratiquer des interventions en cabinet. L'utilisation de la kétamine comme sédatif intraveineux a trouvé des partisans, mais elle est loin de faire l'unanimité. Sa réputation de produire des effets psychologiques indésirables comme des cauchemars, des flashbacks ou des réactions de type schizophrénique a rendu de nombreux anesthésistes et chirurgiens esthétiques réticents à l'employer.

L'auteur fait état de son expérience du protocole kétamine-diazépam auprès d'environ 11400 patients, depuis 1971, au Cosmetic Surgery Hospital, à Woodbridge, en Ontario. Le protocole consiste en l'administration de diazépam par voie intraveineuse, suivie d'une faible dose de kétamine $(0,5 \mathrm{mg} / \mathrm{kg}$ jusqu'à concurrence de $40 \mathrm{mg}) 2$ minutes plus tard. Cela permet au chirurgien d'obtenir une période d'amnésie profonde pour procéder à l'infiltration de l'anesthésique local. C'est cette administration d'anesthésique local durant la période de dissociation qui assure une analgésie prolongée durant la chirurgie. Le patient est maintenu dans cet état tout au long de l'intervention par l'administration progressive de diazépam et de midazolam.

Le protocole est efficace, fiable et reproductible, et l'expérience qu'en ont faite les patients et les chirurgiens esthétiques reçoit un accueil des plus favorables.
$\mathbf{R}$ ising hospital costs and operating room scheduling difficulRties have influenced plastic surgeons to rely more on intravenous sedation in outpatient clinics. This offers both the patient and surgeon more flexibility and makes for more costeffective surgery.

The plastic surgeon should have knowledge of a technique for conscious sedation that is consistent, efficient and, most of all, safe. It must offer amnesia, a stable hemodynamic status during surgery, minimal side effects and a rapid discharge. The patient is able to independantly maintain an airway with a minimal depression of consciousness. A wide variety of drugs such as benzodiazepines, barbiturates, opioids, propofol and ketamine have been used in conscious sedation (1). Midazolam with fentanyl and propofol is a frequently used combination (2).

The use of ketamine as an agent for intravenous dissociation has enjoyed some popularity over the past three decades; however, this has been far from universal. Anesthesiologists and plastic surgeons are reluctant to use ketamine because of its reputation for producing psychological side effects, including disturbing emergent psychic reactions, nightmares, flashbacks and schizophrenic-like reactions.

In 1981, Charles Vinnik reported his extensive experience with anesthesia in an office surgical environment, maintaining that the key to the successful use of ketamine is diazepam (3).

Since 1971, the surgeons at the Cosmetic Surgery Hospital, in Woodbridge, Ontario, have had extensive experience (approximately 11,400 patients) with using a combination of ketamine and diazepam for intravenous sedation. We describe our technique, and give some insight to what we believe is the key to ketamine use.

\section{PHARMACOLOGY}

Ketamine is a phencyclidine derivative that produces true dissociation (ablation of afferent painful stimuli) by acting on numerous central nervous system receptor sites including $\mathrm{N}$-methyl-D-aspartate. Its onset is within one arm-brain 
circulation time $(1 \mathrm{~min})$ and the duration of action is $10 \mathrm{~min}$ to $15 \mathrm{~min}$. It is mostly eliminated through hepatic and renal function and produces a transient elevation of blood pressure and heart rate through its sympathomimetic effect. It also has a bronchodilatory effect and causes an increase in bronchial secretions in a small percentage of patients. It is a shortacting drug that produces analgesia and amnesia.

One of the main advantages of ketamine is that it causes minimal central respiratory depression, and the gag and cough reflexes remain intact. It also has a high therapeutic index, which makes for a wide margin of safety in clinical use. Its main disadvantage is the effect on the central nervous system, causing an increase in the cerebral metabolic rate and lowering the seizure threshold. It can also cause undesirable psychological reactions on emergence, such as vivid unpleasant dreams, excitement, confusion and fear.

\section{METHODS}

\section{Preoperative regimen}

All patients were treated in the Cosmetic Surgery Hospital, which is a private facility located in Woodbridge, Ontario. On the day of surgery, most patients were premedicated with $1 \mathrm{mg}$ of sublingual lorazepam. Starting approximately seven years ago, patients with a history of hypertension and undergoing a facial procedure were also given $0.1 \mathrm{mg}$ to $0.2 \mathrm{mg}$ of oral clonidine, an alpha-2 agonist, that has both analgesic and sedative properties without causing repiratory depression. Clonidine also causes bradycardia and hypotension that may counteract the effects of locally injected epinephrine (4).

\section{Intraoperative regimen}

In the operating room, all patients had intermittent noninvasive automated blood pressure readings every $5 \mathrm{~min}$, pulse oximetry and a continuous electrocardiograph monitored by a registered nurse. Vital signs were recorded every $15 \mathrm{~min}$, during which the patient was breathing room air.

Intravenous diazepam ( $7.5 \mathrm{mg}$ to $15 \mathrm{mg}$ ) was given slowly over $2 \mathrm{~min}$. The slurring of speech and sensation of drowsiness were considered to be clinical end points for dosing. This was followed $2 \mathrm{~min}$ later with intravenous ketamine $(0.5 \mathrm{mg} / \mathrm{kg}$ to a maximum of $40 \mathrm{mg}$ ). This low dose of ketamine was never exceeded initially and was given over a period of $60 \mathrm{~s}$. Then, when the patient was in the dissociative state, local anesthetic was infiltrated $(0.25 \%$ lidocaine with epinephrine $1: 400,000)$.

The patient was maintained throughout the procedure with increments of $1 \mathrm{mg}$ to $2 \mathrm{mg}$ of intravenous midazolam or $5 \mathrm{mg}$ increments of intravenous diazepam. These increments were given if the patient became restless or asked for more sedation, if the oxygen saturation was normal. On occasion, the patient was given another dose of ketamine, consisting of one-half the original dose if the patient needed further infiltration with local anesthetic. Throughout the procedure, the patient's level of consciousness and breathing were monitored closely. The patient rarely needed ancillary oxygen.

Toward the end of the procedure, morphine $2 \mathrm{mg}$ to $4 \mathrm{mg}$ intravenous and $6 \mathrm{mg}$ intramuscularly was generally given for sedation and postoperative pain control, if the blood pressure was normal. After surgery, the patient was taken to the recovery room for monitoring, until the time of discharge.

\section{DISCUSSION}

From 1971 to 2003, approximately 11,400 patients underwent this protocol. Approximately $70 \%$ had facial aesthetic procedures (rhytidectomy, blepharoplasty, brow lift, ancillary facial procedures), 10\% had breast augmentation (both submammary and subpectoral) and $20 \%$ had various cosmetic procedures (eg, localized liposuction). We believe that once proper local anesthesia is used, the patient should not have intraoperative pain; therefore, the purpose of the ketamine injection is to provide the surgeon this window of time of profound amnesia to accomplish the injection adequately.

Benzodiazepines are extremely effective drugs in producing sedation and amnesia, but have few analgesic properties. Other protocols for intravenous sedation include a narcotic agent to achieve analgesia, the effects of which linger for hours. We believe the only time an analgesic is needed is during the local infiltration of the anesthetic. Even when a short-acting narcotic (fentanyl) is used, there would be more respiratory depression because of the synergy between the benzodiazepines and the narcotics (4).

The incidence of intraoperative or postoperative dysphoric reactions (screaming, moaning and hallucinations) was approximately 3\% to $5 \%$. Of these patients, $90 \%$ had no recall of intraoperative events. We found patients who were not induced effectively with intravenous diazepam were not sedated enough and had a higher incidence of dysphoric reactions. Many other techniques (3) find it necessary to have the patient deeply sedated with incremental diazepam before the dose of ketamine; we did not find this to be necessary.

It is well established that there are marked differences between the pharmacological properties of diazepam and midazolam. Midazolam causes less pain on intravenous injection, peaks faster, and is a more effective anxiolytic, sedative and amnesic agent (4). It also has been reported (5) that midazolam is more effective than diazepam in suppressing the cardiovascular and psychotomimetic effects of ketamine. In our experience, we did not find that using one drug over the other had any clinical advantage, except for the incidence of recall. We found that midazolam decreased the incidence of recall and was a better amnesic drug than diazepam.

Ketamine causes a transient increase in systolic blood pressure due to an increase in central venous pressure and cardiac stroke output (6-9). We have counteracted this elevation of blood pressure by placing the patient in a $15^{\circ}$ reverse Trendelenberg position.

For hypertensive patients, blood pressure is well controlled before surgery and in the operating room. If there is no improvement with sedation, we substitute meperidine or morphine for ketamine.

On several occasions, ketamine caused hypersecretion of tenacious mucus in the upper respiratory tract, and in one patient this necessitated clearing the airway with suction (10).

The overall incidence of nausea and vomiting was low in our patients. We found that there was an association between the doses of intraoperative diazepam or midazolam and postoperative nausea and vomiting. Clearly, in other protocols, where narcotics like fentanyl are used instead of ketamine, the incidence of vomiting is higher. 
Although it is well known that ketamine can produce hyperventilation, the addition of other respiratory depressants such as benzodiazepines can increase the risk of hypoxia (11). We experienced this in a single case. The patient, who desaturated, had an oxygen saturation of $45 \%$. The surgery was stopped; the patient was resuscitated and did not require intubation.

Preoperatively, we identify patients with risk factors and morbid conditions. We emphasize patient selection. Patients with a history of drug or alcohol abuse are not good candidates for this protocol.

Patients with uncontrolled hypertension or a history of epilepsy (excluding childhood epilepsy) are better suited to alternative intravenous techniques or general anesthesia.

Although Vinnik (3) reported in his series of 2000 cases that the psychological sequelae were eliminated with the use of diazepam, we believe that the addition of diazepam markedly reduces the incidence, but does not eliminate it completely.

\section{CONCLUSION}

Intravenous diazepam, followed by intravenous low-dose ketamine $(0.5 \mathrm{mg} / \mathrm{kg}$ to a maximum of $40 \mathrm{mg})$, is an effective, reliable and reproducible way of setting the stage for complete and adequate local anesthetic injection. Ketamine is used to provide a dissociated period of $5 \mathrm{~min}$ to $10 \mathrm{~min}$ during which the local anesthetic can be injected. The adequacy of the local infiltration provides analgesia throughout the procedure.

This minimizes repeated increments of sedative and narcotic drugs that might lead to increased postoperative nausea and vomiting, prolonged recovery time and hypoxia.
We find that the experience of the surgeon and the patient alike has been overwhelmingly favourable with this protocol. We find this dissociative technique to be the most versatile in the plastic surgery clinic setting.

\section{REFERENCES}

1. Yoon HD, Yoon ES, Dhong ES, et al. Low dose propofol infusion for sedation during local anesthesia. Plast Reconstr Surg 2002;109:956-63.

2. Marcus JR, Tyrone JW, Few JW, Fine NA, Mustoe TA. Optimization of conscious sedation in plastic surgery. Plast Reconstr Surg 1999;104:1338-45.

3. Vinnik CA. An intravenous dissociation technique for outpatient plastic surgery: Tranquility in the office surgical facility. Plast Reconstr Surg 1981;67:799-805.

4. Moscona RA, Ramon I, Ben-David B, Isserles S. A comparison of sedation techniques for outpatient rhinoplasty: Midazolam versus midazolam plus ketamine. Plast Reconstr Surg 1995;96:1066-74

5. Cartwright PD, Pingel SM. Midazolam and diazepam in ketamine anaesthesia. Anaesthesia 1984;39:439-42.

6. Hirota K, Lambert DG. Ketamine: Its mechanism(s) of action and unusual clinical uses. Br J Anaesth 1996;77:441-4

7. Savege TM, Colvin MP, Blogg CE, Simpson JC, Weaver EJ. Cardio-respiratory effects of some commonly used intravenous induction agents. Acta Anaesthesiol Belg 1974;25:316-29.

8. El-Naggar M, Rao T, Murugia M, Collins VJ. Effect of ketamine in the blood pressure and pulse rate (a comparison with thiopental and fentanyl). Middle East J Anaesthesiol $1975 ; 4: 29-42$.

9. Zsigmond EK, Kelsch RC, Kothary SP. Rise in plasma-free norepinephrine during anesthetic induction with ketamine. Behav Neuropsychiatry 1974-1975;6:81-4.

10. Gordon HL. The selection of drugs in office surgery. Clin Plast Surg 1983;10:277-84.

11. Gruber RP, Morley B. Ketamine-assisted intravenous sedation with midazolam: Benefits and potential problems. Plast Reconstr Surg 1999;104:1823-7. 